\title{
Strength Model of Cementing Filling Body under Lateral Pressure
}

\author{
JunWang ${ }^{1, a}$, Deng-panQiao ${ }^{1, b}$ \\ 1. Faculty of land and resources engineering, Kunming University of Science and Technology, \\ Kunming 650093, China
}

a:867226048@qq.com, b:1215550723@qq.com

Keywords: Cementing filling body; Lateral pressure of tailings; Strength model

\begin{abstract}
In recent years, based on that the research and application of the open stoping with subsequent fill continuous mining method of "two step" model is getting more and more attention. The design of the strength of cementing filling body of the first step ore room is especially important under the condition of the continuous mining. In the paper, the formula of the strength design of cementing filling body was deduced by analyzing the force state of cementing filling body that influenced by lateral pressure of tailings of the second step ore room, the influencing factors that influenced the required strength of cementing filling body and their relationship were fully considered, including the structure size of cementing filling body, the friction between surrounding rock and cementing filling body and the lateral pressure of tailings. Pointing out the influence of the lateral pressure of the bulk mass tailings filling body to the stability and strength design of cementing filling body can't be ignored in the design. There is high practical guiding value to engineering design of the model.
\end{abstract}

\section{Introduction}

Filling mining method can not only maintain the stability of mine and stope, but also improve the recovery rate of mineral resources and protect the environment ${ }^{[1]}$. Based on the above advantages, filling mining method is got more and more wide using. With the wide using of filling mining method, the technique level and the corresponding theoretical research of is also got rapid development. Reasonable strength of cementing filling body is the key of the application of filling mining method. Can cementing filling body provide safe and reliable working environment for stope? On the base of mechanics, it depends on its stress state in the stope ${ }^{[2]}$. Thus, in order to design strength of cementing filling body scientifically, that depends on the research of the stress distribution law of cementing filling body.

\section{Force Analysis of Cementing Filling Body under Lateral Pressure of Tailings}

At present, the research and application of the open stoping with subsequent fill continuous mining method of "two step" model is got more and more attention, its extraction techniques is dividing the ore block into the first step ore room and the second step ore room, mining the first step ore room firstly and filling the formation space by using cemented materials, and then mining the second step ore room and filling the formation space by using tailings. In the extraction process of ore block, the cementing filling body will experience the special mechanics situation of one side exposed, the other side influenced by the lateral pressure of tailings(as shown in Figure 1).

At present, the concept of "self-support" is usually used to design the required strength of cementing filling body, the gravity and exposed area of cementing filling body are mainly considered to the influence of its stability in this method, such as Thomas model ${ }^{[3]}$, Terzaghi model $^{[4]}$ and Thomas model revised by Lu Ping ${ }^{[2]}$. Tailings is particulate medium could be learned from its physical and mechanical properties. It has liquidity and generates lateral pressure on the structure that limits its flow ${ }^{[5]}$. The stress of the cementing filling body that influenced by the lateral pressure of tailings will obviously change ${ }^{[6,7]}$, and the cementing filling body will move a far distance to the exposed side ${ }^{[8]}$. Thus, the concept of "self-support" can't be used to design the 
required strength of cementing filling body which is influenced by lateral pressure of tailings. Based on the concept of "self-support", the influence of the lateral pressure of tailings to the stability of cementing filling body should be considered.

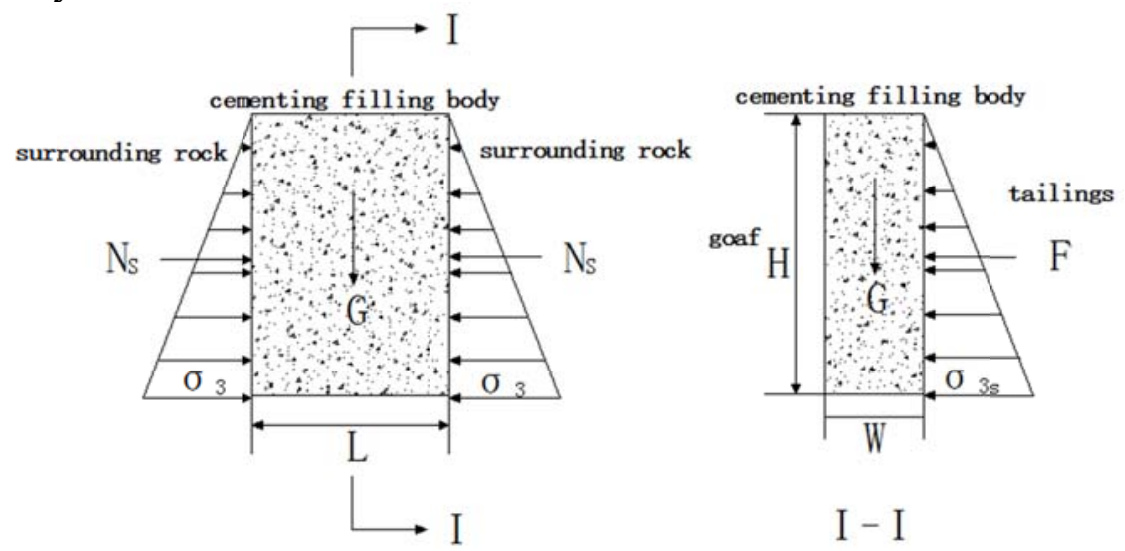

Fig 1 Mechanical environment diagram of cementing filling body

The typical failure of cementing filling body is shear ${ }^{[9,10]}$. Based on the conditions, analyzing the stress state of cementing filling body that one side is exposed and the other side bears the lateral pressure of tailings. To facilitate analysis, simplifying the mechanical model as shown in the Fig 1 toFig 2 .
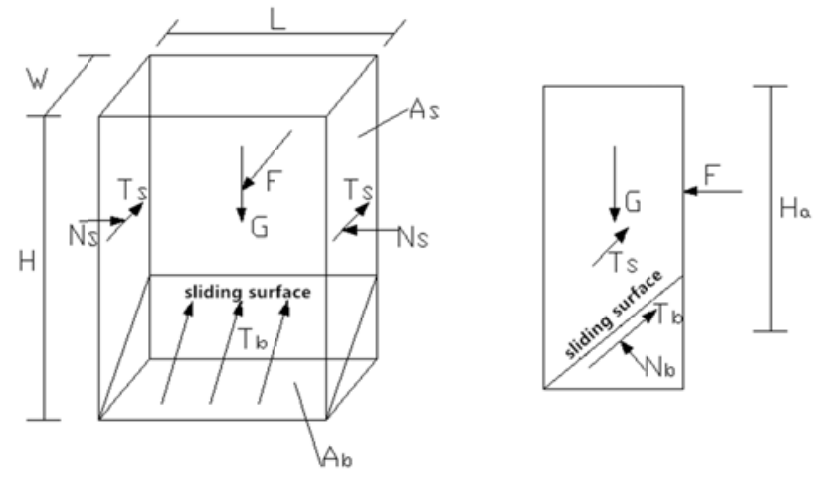

Fig 2 Schematic diagram of mechanical model of cementing filling body

By analyzing Fig 2, that can be learned the cementing filling body balance state is affected by several forces: (1) the gravity of cementing filling body $(\mathrm{G}),(2)$ the lateral pressure of tailings (F), (3) the slip resistance on sliding surface of cementing filling body $\left(\mathrm{T}_{\mathrm{b}}\right)$, (4) the friction between cementing filling body and surrounding rock.

The meaning of the symbols as shown below in figure 2:

Where " $T_{s}$ " is the friction between cementing filling body and surrounding rock, " $T_{b}$ "is the slip resistance on the sliding surface, " $\mathrm{N}_{\mathrm{s}}$ " is the acting force that the surrounding rock acts on the cementing filling body, " $\mathrm{N}_{\mathrm{b}}$ "is the braced force that the cementing filling body under the sliding surface acts on the cementing filling body above the sliding surface, " $G$ " is the gravity of the cementing filling body. " $\mathrm{A}_{\mathrm{b}}$ " is the area of the sliding surface, " $\mathrm{A}_{\mathrm{s}}$ " is the area between cementing filling body and surrounding rock, " $\mathrm{H}$ " is the height of the cementing filling body, "W" is the width of the cementing filling body, "L" is the length of the cementing filling body," $F "$ is the lateral pressure of the tailings that acts on the cementing filling body.

Based on Fig 2, the balance equation of the cementing filling body can be established:

$$
\left.\begin{array}{c}
2 T_{s}+T_{b}-G \sin \alpha-F \cos \alpha=0 \\
N_{b}-G \cos \alpha+F \sin \alpha=0 \\
T_{b}=c A_{b}+N_{b} \tan \varphi \\
T_{s}=c_{j} A_{s}+N_{s} \tan \varphi_{j}
\end{array}\right]
$$

Auxiliary equation: 


$$
\begin{gathered}
A_{b}=L W / \cos \alpha \\
A_{s}=W H_{a}
\end{gathered}
$$

In the auxiliary equation, $\mathrm{H}_{\mathrm{a}}=\mathrm{H}-\mathrm{W} \tan \alpha / 2$, when $\mathrm{H} \gg \mathrm{W}, \mathrm{H}_{\mathrm{a}}=\mathrm{H}^{[2]}$.

For simplicity, supposing:

$$
c_{j}=k_{1} c
$$

$\mathrm{N}_{\mathrm{S}}$ often summed up by $\overline{\sigma_{3}}$ :

$$
\varphi_{j}=\varphi
$$

$$
N_{S}=W H \overline{\sigma_{3}}=W H \frac{\int_{0}^{H} \sigma_{3}(H) d H}{H}
$$

By the above analyzing, bringing the auxiliary equation (2), (3), (4) to the balance equation (1):

$$
\mathrm{c}=\frac{G(\sin \alpha-\cos \alpha \tan \varphi)+F(\cos \alpha+\sin \alpha \tan \varphi)-2 W H \overline{\sigma_{3}} \tan \varphi}{2 k_{1} H W+\frac{W L}{\cos \alpha}}(5)
$$

In the above equation, numerator and denominator with multiplied by $2 \tan \alpha \cos \alpha$ :

$$
\mathrm{c}=\frac{2 G \sin \alpha(\sin \alpha-\cos \alpha \tan \varphi)-4 W H \overline{\sigma_{3}} \tan \varphi \sin \alpha+2 F \tan \alpha \cos \alpha(\cos \alpha+\sin \alpha \tan \varphi)}{4 k_{1} H W \sin \alpha+2 \tan \alpha L W}
$$

When $\varphi=5-45^{\circ}$ :

$$
\begin{aligned}
& 2 \sin \alpha(\sin \alpha-\cos \alpha \tan \varphi)=0.9992-0.9989 \\
& 2 \cos \alpha(\cos \alpha+\sin \alpha \tan \varphi)=1.0008-1.0011
\end{aligned}
$$

According to the above result, equation (6) can be simplified:

$$
\mathrm{c}=\frac{\mathrm{G} / W L-4 H \overline{\sigma_{3}} \tan \varphi \sin \alpha / L+F \tan \alpha / W L}{4 k_{1} H \sin \alpha / L+2 \tan \alpha}
$$

Assuming the cementing filling body meets Tresca yield criterion:

$$
\mathrm{c}=\frac{\sigma_{1}-\sigma_{3}}{2}
$$

Bringing the equation (8) to the equation (7):

$$
\sigma_{1}-\sigma_{3}=\frac{\mathrm{G} / W L-4 H \overline{\sigma_{3}} \tan \varphi \sin \alpha / L+F \tan \alpha / W L}{2 k_{1} H \sin \alpha / L+\tan \alpha}
$$

Under normal conditions, $\sigma_{3}(\mathrm{~h})$ is a nonlinear function, as a matter of convenience, supposing: $\sigma_{3}=2 \overline{\sigma_{3}}(10)$

There is the following relationship between $\sigma_{1}$ and $\sigma_{3}$ :

Thus, $\overline{\sigma_{3}}$ can besummed up by $\sigma_{1}$ :

$$
\begin{aligned}
& \sigma_{3}=\mathrm{k} \sigma_{1}(11) \\
& \overline{\sigma_{3}}=\frac{\mathrm{k} \sigma_{1}}{2}(12)
\end{aligned}
$$

Where " $\mathrm{k}$ " is side pressure coefficient, it is connected with the contact conditions between cementing filling body and surrounding rock, its value is generally 0.1 up to 0.7 , and it can be used to determine byk $=1-\sin \varphi_{\mathrm{j}}^{[11]}$.

After the above analyzing, bringing the equation (11), (12) to the equation (9):

$$
\sigma_{1}=\frac{\mathrm{G} / L W+F \tan \alpha / W L}{(1-k) \tan \alpha+\frac{2 H k_{1}}{L} \sin \alpha\left(1-k\left(1-\frac{\tan \varphi}{k_{1}}\right)\right)}
$$

There is $\mathrm{k}\left(1-\frac{\tan \varphi}{\mathrm{k}_{1}}\right)$ in equation (13), its value is usually far less than landassuming $\mathrm{k}\left(1-\frac{\tan \varphi}{\mathrm{k}_{1}}\right)=\mathrm{k}$, equation (13) can be simplified:

$$
\sigma_{1}=\frac{\gamma H+F \tan \alpha / W L}{(1-k)\left(\tan \alpha+\frac{2 H^{c} j}{L c} \sin \alpha\right)}(14)
$$

$\sigma_{1}$ is equal to $\sigma_{v}$ :

$$
\sigma_{v}=\frac{\gamma H+F \tan \alpha / W L}{(1-k)\left(\tan \alpha+\frac{2 H^{c} j}{L c} \sin \alpha\right)}(15)
$$

Equation (15) can describe vertical stresses distribution of cementing filling body that is influenced by lateral pressure of tailings, it needs to make sure the lateral pressure of tailings when using this equation to design the required strength of cementing filling body. 


\section{Lateral Pressure of Tailings}

The cementing filling body is retaining wall for tailings, it limits the flow of tailings. Therefore, the lateral pressure of tailings acts on cementing filling body. It can be learned by analyzing the stress state of tailings (as shown in Fig 3), that $\sigma_{1 s}$ is the maximal principal stress of any point of tailings, its value is equal to the weight of the overlying tailings, the minimum principal stress $\left(\sigma_{3 s}\right)$ is the stress between tailings and cementing filling body, namely the lateral pressure of tailings that acts on cementing filling body.

The tailings is particulate medium, assuming its cohesion to zero. It can be learned by analyzing the balance state of tailings unit, that its Mohr's circle of stress state is tangent to strength curve, as shown in Fig 4.

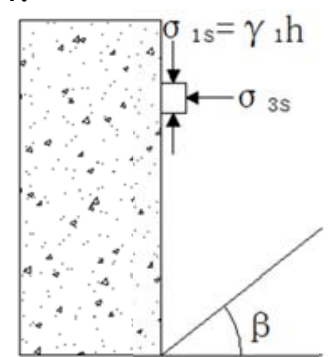

Fig 3Tailings pressure diagram

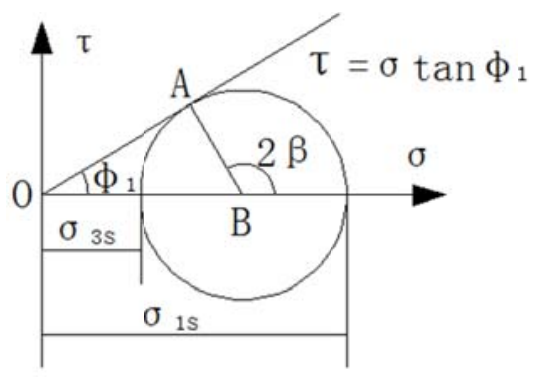

Fig 4Tailings strength curve

It is available by analyzing figure 4 :

$$
\sigma_{3 s}=\sigma_{1 s} \frac{1-\sin \varphi_{1}}{1+\sin \varphi_{1}}=\sigma_{1 s} \frac{\sin \frac{\pi}{2}-\sin \varphi_{1}}{\sin \frac{\pi}{2}+\sin \varphi_{1}}=\sigma_{1 s} \tan ^{2}\left(\frac{\pi}{4}-\frac{\varphi_{1}}{2}\right)=\gamma_{1} h \tan ^{2}\left(\frac{\pi}{4}-\frac{\varphi_{1}}{2}\right)(16)
$$

Equation (16) is the formula to calculate the lateral pressure of tailings that acts on cementing filling body. Considering the contact area between tailings and cementing filling body, the resultant force of lateral pressure of tailings that acts on cementing filling body can be calculation by following equation:

$$
F=\frac{\gamma_{1} H^{2} \operatorname{Ltan}^{2}\left(45^{\circ}-\frac{\varphi_{1}}{2}\right)}{2}
$$

\section{Strength Model of Cementing Filling Body under Lateral Pressure}

Bring Equation (17) to Equation (15):

$$
\sigma_{v}=\frac{\gamma H+\frac{\gamma_{1} H^{2} \tan ^{2}\left(45^{\circ}-\frac{\varphi_{1}}{2}\right) \tan \alpha}{2 W}}{(1-k)\left(\tan \alpha+\frac{2 H^{c} j}{L c} \sin \alpha\right)}(18)
$$

Equation (18) is the strength model of cementing filling body under lateral pressure.

Where $\sigma_{\mathrm{v}}$ is the required strength of cementing filling body (Mpa), $\mathrm{H}$ is the length of cementing filling body $(\mathrm{m}), \mathrm{W}$ is the width of cementing filling body $(\mathrm{m}), \mathrm{L}$ is the length of the cementing filling body $(\mathrm{m}), \gamma$ is the density of cementing filling body $\left(\mathrm{MN} / \mathrm{m}^{3}\right), \gamma_{1}$ is the density of tailings $\left(\mathrm{MN} / \mathrm{m}^{3}\right), \alpha$ is shear angle of cementing filling body $\left({ }^{\circ}\right), \varphi$ is the internal friction angle of cementing filling body $\left({ }^{\circ}\right), \varphi_{1}$ is the internal friction angle of tailings $\left({ }^{\circ}\right), \mathrm{k}$ is side pressure coefficient, it is connected with the contact conditions between cementing filling body and surrounding rock, the value is generally between 0.1 up to 0.7 , and can be determined byk $=1-\sin \varphi_{j}, c_{j}$ is the cohesion between surrounding rock and cementing filling body (Mpa), $c$ is the cohesion of cementing filling body (Mpa), the value of $c_{j} / c$ is generally between 0.6 up to $1.0^{[11]}$.

Not only the structure size, strength parameters and the friction force between cementing filling body and surrounding rock were considered, but also the lateral pressure of tailings. 


\section{The Relationship between the Required Strength of Cementing Filling Body and Influencing Factors}

The relationship between the required strength of cementing filling body and the structure size as shown in figure $5,6,7$.

It can be learned from Fig 5 that, under the same conditions, the required strength of cementing filling body increases with the increase of the cementing filling body height. The gravity of cementing filling body and the lateral pressure of tailings will increase with the increase of its height. On the sliding surface, the component force of them is collapsing force that causing the shear failure of cementing filling body. Therefore, the strength of cementing filling body should be increased to maintain the stability of cementing filling body.

It can be learned from Fig 6 that, under the same conditions, the required strength of cementing filling body increases with the increase of the cementing filling body length. With the increase of its length, the cementing filling body gradually becomes a thin plate, its bearing capacity becomes weak, and the resultant force of lateral pressure of tailings gradually increases. All the above factors will cause the failure of cementing filling body. Therefore, the strength of cementing filling body should be increased to maintain the stability of cementing filling body.

It can be learned from Fig 7 that, under the same conditions, the required strength of cementing filling body decreases with the increase of the cementing filling body width. With the increase of the width, the contact area and the friction between cementing filling body and surrounding rock will increase, that will weaken the influence of gravity of cementing filling body and the lateral pressure of tailings to the stability of cementing filling body. All the above factors make the stress in the cementing filling body decrease. It can be figured out that increasing the width is beneficial to the stability of cementing filling body.

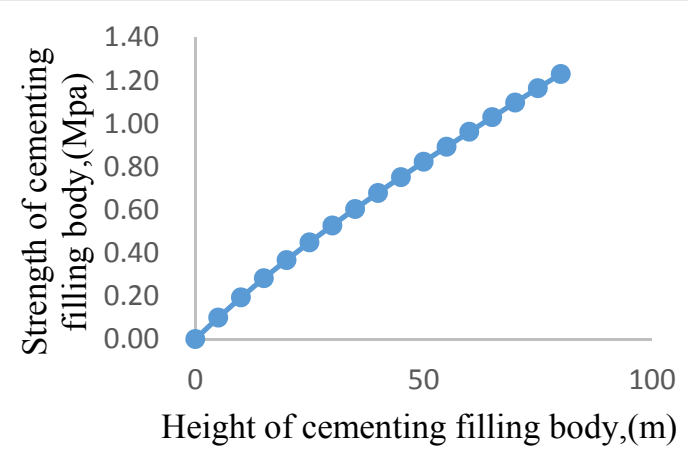

Fig 5 The relationship between strength and

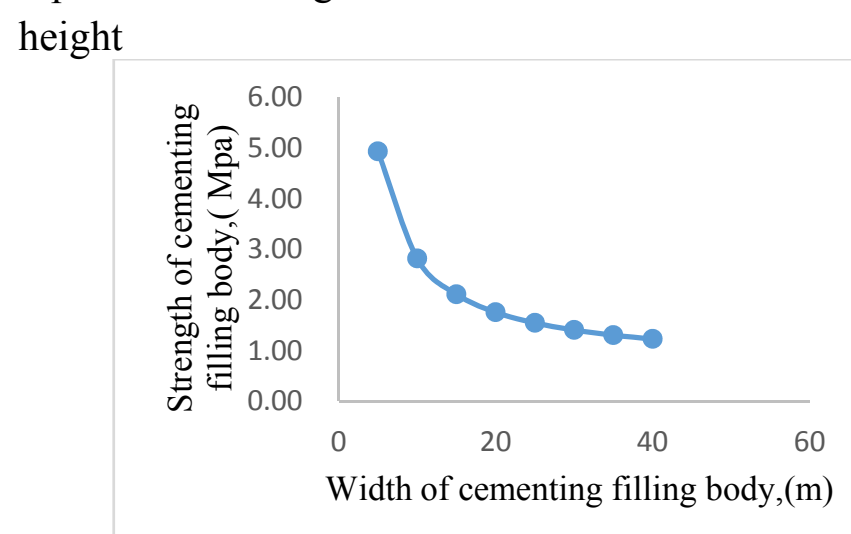

Fig7The relationship between strength and width

The relationship between the required strength of cementing filling body and the physical and mechanical properties as shown in figure 8,9 . 

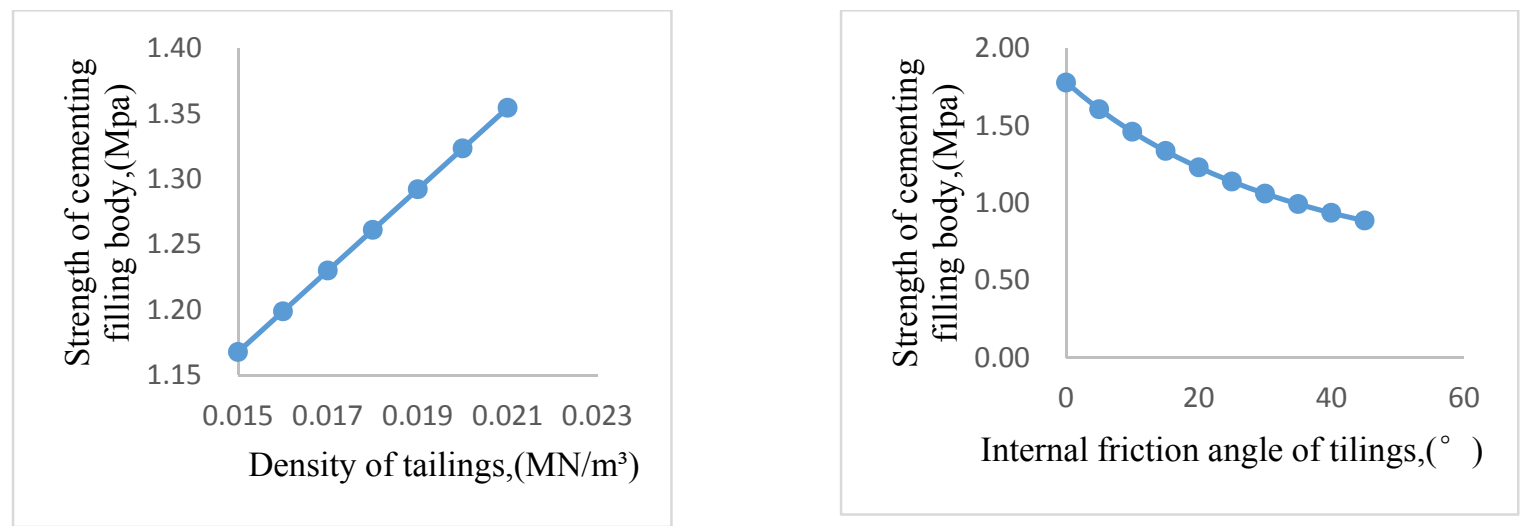

Fig 8 The relationship between strength and tailings' density

Fig 9 The relationship between strength and tailings' internal friction angle

It can be learned from Fig 8 that, under the same conditions, the required strength of cementing filling body increases with the increase of the density of tailings. With the increase of the density of tailings, the lateral pressure of tailings will increase. On the sliding surface, its component force is one of the collapsing force that causing the shear failure of cementing filling body. Therefore, the strength of cementing filling body should be increased to maintain the stability of cementing filling body.

It can be learned from Fig 9 that, under the same conditions, the required strength of cementing filling body decreases with the increase of the internal friction angle of tailings. The internal friction angle is one of the indexes of the shear strength of tailings, the higher values of the internal friction angle, the more stable the tailings, the less the effect of the lateral pressure of tailings to the cementing filling body. Therefore, the stress will decrease in the cementing filling body and then its required strength will decrease.

\section{Summary}

Under the condition that one side is exposed and the other side influenced by the lateral pressure of tailings, through the analysis of the mechanical functions and stress state of cementing filling body, main conclusions are summarized as follows:

(1) When one side of cementing filling body is exposed, the other side bears the lateral pressure, the cementing filling not only need to be self-support, but also act a retaining wall to limits the flow of tailings.

(2) The strength model was established by analyzing the stress state of cementing filling body which one side is exposed, the other side bears the lateral pressure. Strength model is as follows:

$$
\sigma_{v}=\frac{\gamma H+\frac{\gamma_{1} H^{2} \tan ^{2}\left(45^{\circ}-\frac{\varphi_{1}}{2}\right) \tan \alpha}{2 W}}{(1-k)\left(\tan \alpha+\frac{2 H}{L} \frac{c_{j}}{c} \sin \alpha\right)}
$$

(3) The reasonability of the strength model was proved by analyzing the relationship between the required strength of cementing filling body and its influencing factors. There is high practical guiding value to engineering design of the model.

\section{Acknowledgments}

This work was financially support by National Natural Science Foundation of China (51164016).

\section{References}

[1] Si-jing Cai. Mechanics Basis for Mine Filling[M]. Beijing:Press of Metallurgy Industry. 2009.

[2] PingLu. The stress distribution in cemented fill pillar [J]. Gold, 1988, 9(8):9-12.

[3] Thomas E G, et al. Fill Technology in Underground Metalliferous Mines[M]. Ontario, Canada: 
Interna. Acad. Serv. Ltd.,1979.

[4] Terzaghi. K. Theoretical Soil Mechanics [M]. New York: J. Wiley \& Sons, 1943.

[5] Deng-pan Qiao. Theory Research and Application of Ore Drawing [M]. Kunming: Yunnan Science and Technology Publishing Press.2006.

[6] Zheng-song Yang. Research on high efficiency and low loss and wasteless technique for Dahongshan copper mine [D]. Hunan: Central South University, 2011:46-49.

[7] Zhi-xiang Liu. Mechanics of high tailings backfill and nonlinear optimal design in deep mining [D]. Hunan: Central South University, 2005:69-72.

[8] JianYu, Gui-huang Wang. Analysis of cement pillar stability based on hyperstatic structure theory and numerical simulation [J]. Science and Technology Review, 2014, 32(22): 37.

[9] Smith J D, et al. Large scale model tests to determine back fill strength requirements for pillar recovery at the Black Mountain mine[C].Mining with Backfill, Proc. of Interna. Symp. , Lulea, Sweden, 1983.

[10] Bao-gui Yang, Heng-hu Sun, Bai-hong Zhuang. Self-support of high water material solidifying backfill body [J]. Nonferrous Metals, 2000, 52(2): 7-8.

[11] PingLu. Strength deign of cemented fill pillar [J]. South Institute of Metallurgy, 1988, 9(6): 51. 